\title{
Carcinoma in plantar ulcers in leprosy
}

\author{
R N FLEURY \& D V A OPROMOLLA \\ Hospital Lauro de Souza Lima, Rodovia Bauru-Jaú, Km 385, CEP \\ 17.100 Bauru, Estado de São Paulo, Brazil
}

\section{Accepted for publication 9 March 1984}

\begin{abstract}
Summary The authors studied carcinoma arising in plantar ulcers (PUs) in 16 patients having leprosy, admitted to the Lauro de Souza Lima Hospital (Bauru, São Paulo, Brazil) from 1970 to 1982. In a study of the evolutional, clinical and pathological aspects, the main conclusions of interest were:

1 The apparent rarity of these neoplasms must be related to the fact that many observed cases are not recorded;

2 The carcinomas occur chiefly in patients of the borderline group;

3 The carcinomas have in general an ulcero-vegetating appearance, large extension and depth, and preferential situation on the proximal third of the sole of the foot;

4 Having in mind the low frequency of lesions of PUs in the foot proximal third, the incidence of carcinoma in this site can be considered relatively high;

5 From the histological point of view, the majority of tumours were well differentiated, and showed peculiarities similar to those in verrucous carcinoma, in giant condyloma acuminata and in epithelioma cuniculatum plantare;

6 The great tendency to extension of these neoplasms and the possibility of regional metastasis justify treatment by amputation.
\end{abstract}

\section{Introduction}

The greatest problem found in leprosy is its tendency to affect the peripheral nervous system.

This tendency, in the lower limbs leads to sensory, motor and trophic disturbances leading to trophic ulcers. These, in their turn, if not adequately treated, affect the soft parts and the bones, causing progressive deformity in the foot, often leading to the need for amputation.

Plantar ulcers (PU) are a frequent complication of leprosy. Their long duration, frequent trauma, and the osteomyelitis which often follow, would be predisposing conditions for malignant transformation. The neoplasms which take place in PUs are not very common according to cases recorded in the 
Table 1. Clinical and pathological data

Leprosy Leprosy PU Tumour Bone Histol. Follow- Present Initial Case Sex Age type duration duration duration Location involv. grade up condition letters

\begin{tabular}{|c|c|c|c|c|c|c|c|c|c|c|c|c|}
\hline 1 & $\mathrm{M}$ & $43 \mathrm{yr}$ & TRi & $30 \mathrm{yr}$ & $25 \mathrm{yr}$ & $1 \mathrm{yr}$ & $\begin{array}{c}\text { Left } \\
\mathrm{P}\end{array}$ & Yes & I & $2,5 \mathrm{yr}$ & Well & JGS \\
\hline 2 & $\mathrm{M}$ & $68 \mathrm{yr}$ & $\mathrm{Ba}$ & $33 \mathrm{yr}$ & $6 \mathrm{yr}$ & $3 \mathrm{mo}$ & $\begin{array}{c}\text { Lef } t \\
D\end{array}$ & $?$ & I & ? & $?$ & BFG \\
\hline 3 & $\mathrm{M}$ & $31 \mathrm{yr}$ & $\mathrm{Ba}$ & $20 \mathrm{yr}$ & ? & $?$ & $\begin{array}{c}\text { Right } \\
\text { P.M.La }\end{array}$ & Yes & II & $1 \mathrm{yr}$ & Died* & LFBC \\
\hline 4 & $\mathrm{~F}$ & $71 \mathrm{yr}$ & $\mathrm{Bi}$ & $17 \mathrm{yr}$ & $6 \mathrm{yr}$ & $?$ & $\begin{array}{c}\text { Right } \\
\text { P }\end{array}$ & Yes & I & $8 \mathrm{yr}$ & Well & LCM \\
\hline 5 & $\mathrm{M}$ & $62 \mathrm{yr}$ & $\mathrm{Bi}$ & $30 \mathrm{yr}$ & $30 \mathrm{yr}$ & $5 \mathrm{yr}$ & $\begin{array}{c}\text { Right } \\
\text { P }\end{array}$ & Yes & I & $6 \mathrm{yr}$ & Well & SG \\
\hline 6 & $\mathrm{M}$ & $61 \mathrm{yr}$ & $\mathrm{Bi}$ & $40 \mathrm{yr}$ & $25 \mathrm{yr}$ & $1 \mathrm{yr}$ & $\begin{array}{l}\text { Left } \\
\text { M.La }\end{array}$ & Yes & II & $6 \mathrm{yr}$ & Well & $\mathrm{JA}$ \\
\hline 7 & $\mathrm{M}$ & $73 \mathrm{yr}$ & $\mathrm{Bi}$ & $24 \mathrm{yr}$ & $13 \mathrm{yr}$ & ? & $\begin{array}{c}\text { Right } \\
\text { P }\end{array}$ & No & I & $6 \mathrm{yr}$ & Well & $\mathrm{APO}$ \\
\hline 8 & $\mathrm{~F}$ & $65 \mathrm{yr}$ & $\mathrm{Li}$ & $58 \mathrm{yr}$ & $31 \mathrm{yr}$ & $?$ & $\begin{array}{l}\text { Right } \\
\text { P.M.D. }\end{array}$ & $?$ & II & $2 \mathrm{yr}$ & Died $\S$ & IB \\
\hline 9 & $\mathrm{M}$ & $56 \mathrm{yr}$ & $\mathrm{Bi}$ & $31 \mathrm{yr}$ & $3 \mathrm{yr}$ & $2 \mathrm{yr}$ & $\begin{array}{l}\text { Right } \\
\text { P }\end{array}$ & No & I & $11 \mathrm{yr}$ & Died $\dagger$ & $\mathrm{RB}$ \\
\hline 10 & $\mathrm{M}$ & $55 \mathrm{yr}$ & $\mathrm{Ti}$ & $20 \mathrm{yr}$ & $20 \mathrm{yr}$ & $?$ & $\begin{array}{l}\text { Right } \\
\text { P }\end{array}$ & Yes & I & $7 \mathrm{yr}$ & Died $\ddagger$ & DD \\
\hline 11 & $\mathrm{~F}$ & $71 \mathrm{yr}$ & $\mathrm{Ti}$ & $40 \mathrm{yr}$ & $23 \mathrm{yr}$ & $4 \mathrm{yr}$ & $\begin{array}{l}\text { Right } \\
\text { P.M. }\end{array}$ & No & I & $4,5 \mathrm{yr}$ & Well & $\mathrm{LT}$ \\
\hline 12 & $\mathrm{~F}$ & $55 \mathrm{yr}$ & $\mathrm{Li}$ & $34 \mathrm{yr}$ & $1 \mathrm{yr}$ & $?$ & $\begin{array}{l}\text { Right } \\
\text { P.La }\end{array}$ & Yes & II & $3 \mathrm{yr}$ & Well & IF \\
\hline 13 & $\mathrm{M}$ & $60 \mathrm{yr}$ & $\mathrm{Bi}$ & $13 \mathrm{yr}$ & $10 \mathrm{yr}$ & $2 \mathrm{yr}$ & $\begin{array}{l}\text { Right } \\
\text { D.La }\end{array}$ & Yes & I & $4 \mathrm{yr}$ & Well & JJ \\
\hline 14 & $\mathrm{M}$ & $68 \mathrm{yr}$ & $\mathrm{Li}$ & $38 \mathrm{yr}$ & $20 \mathrm{yr}$ & $2 \mathrm{mo}$ & $\begin{array}{c}\text { Left } \\
P\end{array}$ & Yes & I & $4 \mathrm{yr}$ & Well & ABII \\
\hline 15 & $\mathrm{M}$ & $65 \mathrm{yr}$ & $\mathrm{Li}$ & $31 \mathrm{yr}$ & $15 \mathrm{yr}$ & $3 \mathrm{mo}$ & $\begin{array}{l}\text { Right } \\
\text { D.La }\end{array}$ & No & I & $2 \mathrm{yr}$ & Well & JSII \\
\hline 16 & $\mathrm{M}$ & $61 \mathrm{yr}$ & $\mathrm{Bi}$ & $23 \mathrm{yr}$ & $?$ & ? & $\begin{array}{c}\text { Left } \\
\mathrm{D}\end{array}$ & No & I & $1,5 \mathrm{yr}$ & Well & GAS \\
\hline
\end{tabular}

M, male; F, female; T, tuberculoid leprosy; TR, reactional tuberculoid leprosy; B, borderline leprosy; i, inactive; a, active; Location in plantar foot: $\mathrm{P}$, proximal; $\mathrm{M}$, middle; D, distal; La, lateral aspect.

* Metastasis.

$\dagger$ Renal insufficiency.

$\ddagger$ Renal insufficiency.

$\S$ Unknown cause. 
literature..$^{2,4,7,8,13,17,21-3}$ However, the serious course of some of these cases, with infiltration of neoplasms in the bony parts and metastasis, justifies further study.

The aim of this work is to describe squamous cell carcinomas, which occurred in PUs in patients of the Hospital Lauro de Souza Lima (Bauru, São Paulo, Brazil) from 1970 to 1982 .

\section{Results}

Table 1 includes the main clinical and pathological data. We present some details about the clinical records of 3 patients.

Case 1. JGS A 43-year-old male was admitted in September 1979 for a chronic ulcer of 25 years' duration in the left heel, that had become worse 1 year ago. The patient had been under treatment for reactional tuberculoid leprosy for 30 years. His disease began with numbness in the hands and feet, right claw hands and large, elevated, red patches over the face and the limbs. The Mitsuda reaction was positive. The skin lesions disappeared after 1 year under sulphone therapy. $\mathrm{He}$ presented no skin lesions of leprosy but had bilateral claw hands and an ulcer with a whitish, fungating, $15-\mathrm{cm}$ diameter mass, over the postero-lateral aspect of the left heel. Left inguinal lymph nodes were slightly enlarged, firm, not tender and mobile. A clinical diagnosis of squamous cell carcinoma grade I was confirmed by biopsy. A below-knee amputation of left leg and a block dissection of the left inguinal lymph nodes were carried out. The amputated leg was submitted to extensive histopathological examination including the lymph nodes. The tumour invaded all the layers of sole including the underlying bone. The lymph nodes showed no evidence of tumour metastasis. The patient had an uneventful recovery and was discharged in November 1980.

Case 3. LFBC A 31-year-old male was admitted in April 1975 for chronic ulcers in both feet of several years duration. Twenty years previously he had noticed erythematous patches on his trunk and right thigh. Under sulphone therapy the lesions disappeared but he took regular treatment until now. He was classified as a borderline case. On physical examination the patient was found to have hypochromic patches on his trunk and on the upper and lower extremities. Both hands showed ulnar palsy and the fingers were clawed, contracted and shortened to various degrees. The foref eet were shortened from bone reabsorption of phalanges and metatarsals. Both feet showed trophic ulcers. On the heel of the right foot there was an ulcer with proliferating granulation tissue.

As there was a clinical suspicion of malignancy a biopsy sample was taken in June 1975. It revealed a squamous cell carcinoma grade II. In July 1975 a below-knee amputation was performed. In September, enlarged, firm, tender inguinal lymph nodes were noticed and a block dissection was carried out, and a histopathological examination of the nodes showed a secondary squamous cell carcinoma. Three months later a deep, large, firm, nodule was noted over the 
posterior aspect of the right thigh. A biopsy from this lesion showed again metastasis of squamous cell carcinoma. In February 1976 new metastatic nodules appeared besides the previous one. In April 1976 the patient was weak, anaemic and dehydrated. In May 1976 total fracture of 7 th rib was noted and thereafter a 2 $\mathrm{cm}$ fast-growing metastatic nodule became obvious on the external bone. In June the patient was cachectic and wanted to go home, where he died.

Case 9. RB A 56-year-old male, was admitted in April 1940, and presented erythematous patches on his trunk, arms, buttocks and thighs, and wasting of his hands. Bacteriology was negative and he was classified as a borderline leprosy patient. He was discharged in May 1941. In July 1968, he was admitted with PU on his right foot and reported digestive complaints. At that time he presented muscle wasting and bone reabsorption in his hands and well-defined isolated and also confluent erythematous-hypochromic patches with marginal erythema, covering extended zones of trunk. He was under irregular sulphone therapy. In May 1970 he was admitted again with PU on the right side. The cutaneous leprosy lesions had disappeared. However, he presented muscle wasting and clawed hands, foot drop on the right side, ulceration in the right calcaneum with a vegetating base PU in that foot, $\mathrm{PU}$ in the left foot and bone reabsorption in both feet with amputation of some toes. There were not painful inguinal enlarged lymph nodes on the right side. The patient mentioned an increase of vegetation in PU of the calcaneum 2 years before admission, but it had been unaltered since then. In face of the clinical suspicion of carcinoma, several biopsies were performed, and the clinical assumption was confirmed after the 4th biopsy. A below-knee amputation was carried out in October 1971 and a lymph node removed from the inguinal region did not show any evidence of metastasis. The patient was without problems post-operatively, being discharged 7 March 1972. After this he was re-admitted several times due to renal insufficiency which became worse till he died, 19 February 1982.

\section{Discussion}

\section{CLINICAL ASPECT}

When we talk about cancer, in a general way, it does not seem that there are many differences between its incidence in leprosy patients or healthy individuals. But in relation to cutaneous and mucous neoplasms it seems that there is a greater incidence in lepromatous leprosy patients. ${ }^{15}$

In 1961, Leiker ${ }^{12}$ found only 47 cases to assess and drew attention to the scarcity of references on the incidence of carcinoma in leprosy. It was noted that all related cases originated from the Iberian Peninsula and South America and that no case had been found in Africa, Indies, Philippines and some zones of the Pacific Ocean where the incidence of leprosy is very high. It was considered 
unlikely ${ }^{12}$ that there were no cases in these zones but more probable that they had simply not been recorded.

Until 1966 only 94 cases of cutaneous and mucous carcinomas in leprosy patients had been recorded; 32 of these were from Brazil. ${ }^{14}$

In 1966, one study ${ }^{15}$ reviewed 40,000 biopsies on the files of the Departamento de Profilaxia da Lepra (São Paulo, Brazil) from 1930-65. This revealed 539 diagnoses of carcinomas of skin and mucous membrane in leprosy patients, bringing the total of cases found to 633 .

With regard to the incidence of neoplasm in PUs there are few references in literature. This must surely be related more to the fact that cases have not been recorded than to their scarcity, as already mentioned. ${ }^{12}$ This study ${ }^{12}$ found no reason for the greater or lesser incidence of cutaneous carcinoma in leprosy patients than in healthy individuals of the same age, same race and similar conditions, except to confirm that the trophic lesions are very chronic and submitted to constant irritation. The first case mentioned in literature ${ }^{7}$ was in 1942 which also referred to another similar case mentioned by Yashinobu Hayashi. Other studies, 2, 4, 8, 13, 17, 21-3 including our own, brought the number of cases described (until 1982) to a total of 33 .* $^{*}$

It seems that neoplasma arise mainly in PUs of long duration. In our observations, the patients presented PUs from 3 to 30 years' duration and this long duration was also mentioned for all the other cases described. It is important however, to emphasize that reports from patients are often incorrect. They often report that the lesion appeared 4 or 5 years ago but during this time it healed more than once and published accounts are not always clear as to the precise identity of the foot ulcer in which carcinoma eventually develops.

The same problem occurs when we try to establish the time when malignant transformation happened; most of the information is not very precise. There are patients who get used to their lesions and do not notice changes; when asked about duration they are inclined to say that changes have taken place only recently. Others do not know whether there was any change in the appearance of the lesions. In our cases, the time of the change would seem to have occurred in 8 cases between 2 months and 4 years before the diagnosis of the neoplasm. There is, however, in some published cases greater accuracy as to the moment of this change. 8,22

The incidence of cases with malignant change is actually a very small number, if you take into account the high incidence of PUs in leprosy patients. In our hospital, a survey carried out in 1970 , showed that $10 \%$ of our patients presented PUs. Other authors refer to a greater prevalences $15 \cdot 7 \%{ }^{16}$ and $11 \cdot 7 \%{ }^{19}$ The age: of patients in whom neoplasms occur vary considerably, but all cases described were 30 years old or more. In our patients age varied between 31 and 73 years. Women are less affected than men, if we judge the available data. This could be related to a

${ }^{*}$ In 1981 , a case of carcinoma in trophic ulcer is referred to ${ }^{18}$ but the site of the lesion is not indicated. 
lesser incidence of PUs in women or to the greater care they take with their lesions, lessening their chronicity.

Malignant change in plantar ulcers seems to occur more frequently in dimorphous and tuberculoid patients. The majority of our cases belonged to these clinical forms and also those described by Job \& Riedel, ${ }^{8}$ Srinivasan \& Desikan.22 Probably this would be related to the greater incidence of PUs in patients of these clinical forms due to a greater neurological involvement.

The appearance of the neoplasm is variable; in the majority of cases the border of the lesion becomes more prominent, everted and the base in general becomes vegetating. There are lesions which become bulky and rounded, adopting the 'cauliflower' aspect ${ }^{22}$ or resembling the giant condyloma acuminatum. ${ }^{3,6,9}$

Other lesions also form exophytic masses which infiltrate through the sole forming fistulous channels, which assume a vegetating appearance when they occur in the other parts of the foot (Figure 2). These fistulae also invade the bony plane and show an identical appearance to that described in the epithelioma cuniculatum pedis $1,5,17,20$ (Figure 3).

Symptomatology is minimal. Some cases described refer to local pain and others to easy bleeding. Only our case No. 1 ref erred to bleeding, and pain was not a frequent complaint.

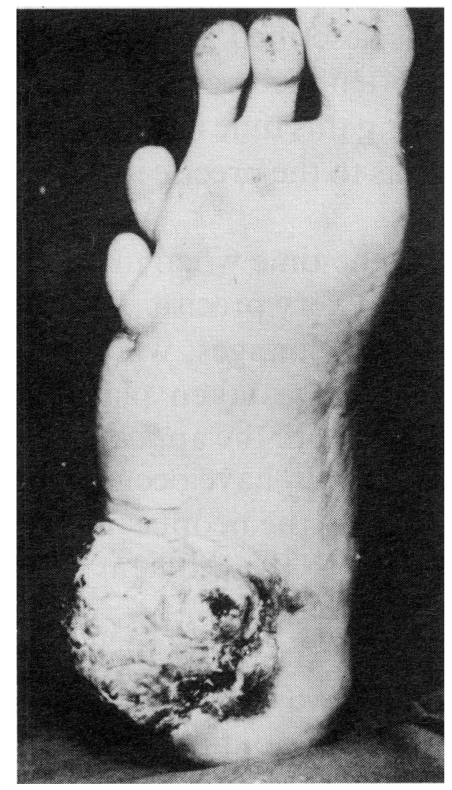

Figure 1.

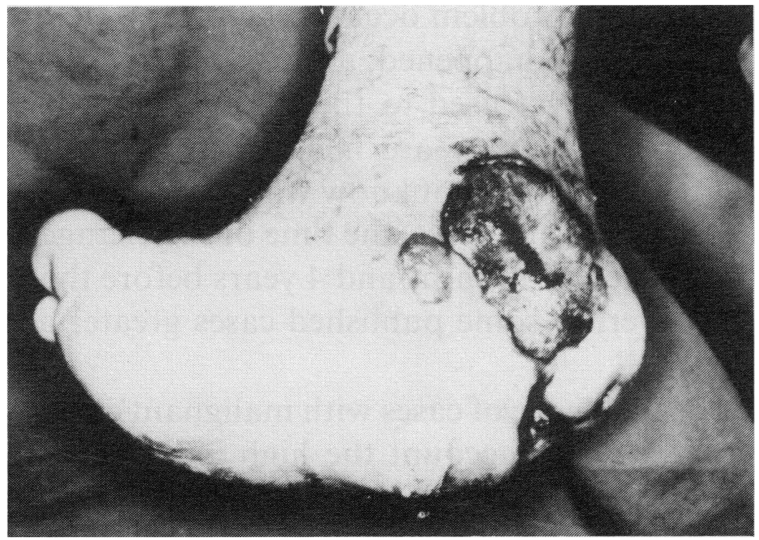

Figure 2.

Figure 1. Case 10-Squamous cell carcinoma (Grade I) Extended tumoral lesion of the foot, proximal third. Bone reabsorption at the distal third.

Figure 2. Case 3-Squamous cell carcinoma (Grade II) Ulcerous and vegetating tumoral lesions, proximal third and lateral aspect of the left foot. 


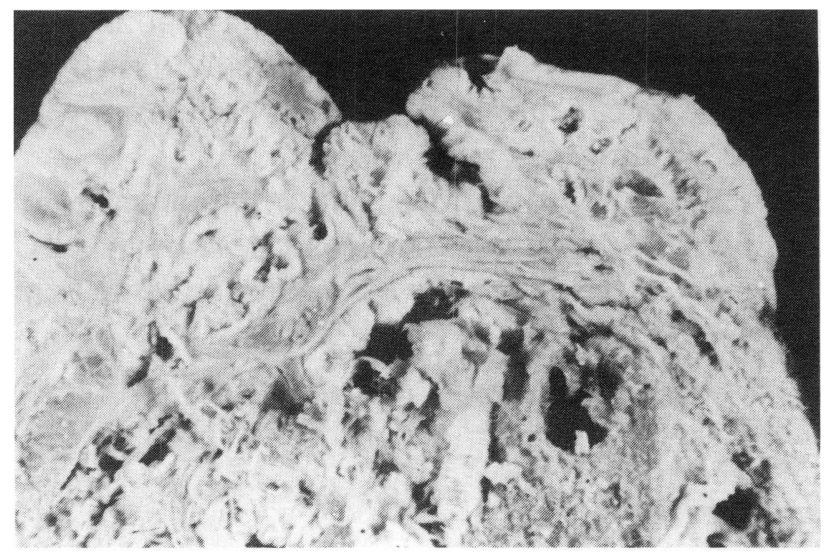

Figure 3. Case 14 Squamous cell carcinoma (Grade I) neoplastic extension into bone and formation of crypts.

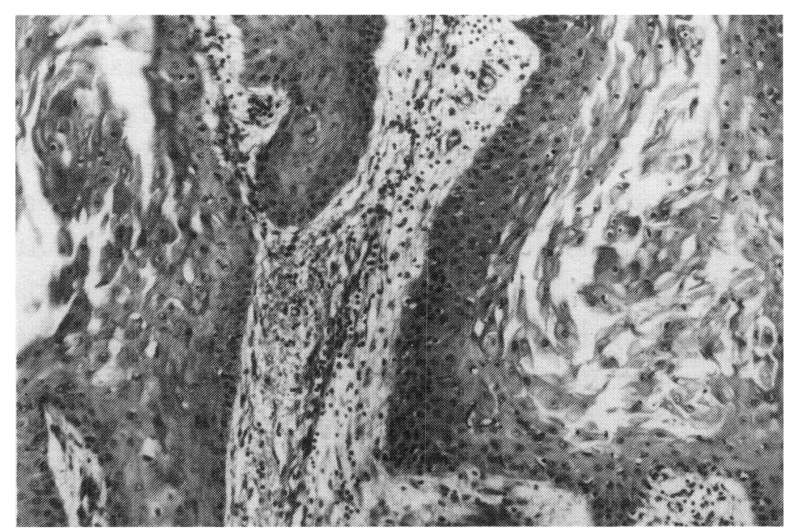

Figure 4. Case 11-Squamous cell carcinoma (Grade I) Disaggregation of horn cells. Initial formation of crypts.

The site of neoplasm in the sole is in general in the proximal third (Figure 1). Two cases described by Job \& Riedel ${ }^{8}$, the cases of Riedel, ${ }^{21}$ the 2 cases of Boopalraj \& Muthusami, ${ }^{4} 1$ of Srinivasan \& Desikan ${ }^{22}$ and 11 of our cases involved this site. Another site is in the lateral border of the foot. In these cases the patient presents his foot in echino-varo, ankylosed in that position. The support site of the foot, being not used to bear high pressures, wounds itself and the lesions open easily. Those which become malignant form vegetating masses which invade the back of the foot and open fistulae in several sites of the calcaneum. The reason for the most frequent site at the proximal third of the sole would be the greater chronicity of these lesions which lead to osteomyelitis of long duration, disintegrating the tarsus bones structure, coming even near to destruction of the tibial-tarsal joint. Lesions of the distal third of the sole are relatively of a lesser 
duration because the metatarsal and the phalanx are bones with lesser size and width and because of this they can be more quickly destroyed or reabsorbed. Incidence of PU at the calcaneum level is low if compared with the other sites. About $5 \%$ in Indies; ${ }^{4} 7 \%$ in our series.

Perhaps because of this, squamous cell carcinoma is not seen with the frequency which might be expected for chronic lesions like PUs. On the other hand, the incidence is relatively high if we consider only the trophic ulcers of the calcaneum.

\section{PATHOLOGICAL ASPECTS}

The distinction between a hyperplastic pseudo-epitheliomatous reactivity and a well-differentiated carcinoma was very difficult in the pre-operative biopsies. In 1 of the cases, 6 biopsies were performed before a final diagnosis could be made. The analysis of the cytological alterations (pleomorphism, mitoses, atypical cells, etc.) was useful in only 4 cases, in which the carcinoma was considered of grade II. In the remaining well-differentiated cases (grade I), the diagnosis was mostly based in the depth and on the infiltrative features of the epithelial projections. The analysis of our cases showing extensive infiltrative tumoral masses, often involving bone, made us consider the lesions as malignant by analogy with other human neoplasms in which the diagnosis of malignancy is based on a careful evaluation of the clinical and pathological data. Examples of these neoplasms are verrucous carcinoma, the giant condyloma acuminatum and the epithelioma cuniculatum pedis. ${ }^{1,}, 5,6,6,10,20$ Concomitantly, in the evaluation of the degree of malignancy of the neoplasm we found, after microscopical examination, some peculiar histological characteristics already mentioned in cases of carcinoma in this location, $1,5,17,20$ suggesting a possible relationship with the verrucous carcinoma, as reported by Brownstein \& Shapiro. ${ }^{5}$ The characteristics are the following:

1 Papillomatosis, hyperkeratosis and parakeratosis with formation of an actual keratinic plug which gets deeper in the depressions of the hyperplastic epithelium. In this epithelium, the intercellular bridges are not visible and the layer of squamous cells is made of voluminous, polygonal cells with abundant, homogenous and acidophilic cytoplasm. These features, described in the verrucous carcinoma and in the epithelioma cuniculatum pedis ${ }^{20}$ were present in all but one of our cases.

2 Keratinization and disaggregation of the squamous cells forming real crypts at the level of the epithelial projections (Figure 4). This alteration was observed in 8 cases $(1,3,4,6,11,13,14$ and 15$)$; in 6 cases $(1,4,6,13,14$ and 15) the crypts were macroscopically visible. Aird et al. ${ }^{1}$ think these changes occur due to an excessive keratinization which is characteristic of the epithelium in this localiza- 
tion. Similar changes, however, are described in the verrucous carcinoma located in the floor of the mouth and in the giant condyloma acuminatum..$^{1,3,5}$

From the evolutive point of view, not even all the tumours are restricted to local growth, without metastasis and an effect on the general condition. A case of Hayashi \& Fukuda, ${ }^{7} 2$ cases of Job \& Riedel, ${ }^{8}$ a case of Riedel ${ }^{21}$ and 1 of our patients had metastasis and 3 of these patients died.

Summarizing, carcinoma which arises in the PUs of leprosy patients, must be more common than the literature dealing with this matter suggests, chiefly those arising in PUs of the proximal third of the sole. They can lead to death with metastasis in the regional lymph nodes and systemic sites.

The PUs of the calcaneum are easily treated with adjustments in the shoes or when they are extended, by surgical operations. When they have not been adequately treated and present malignant transformation, amputation is indicated, ${ }^{5,11}$ if we consider the clinical presentation of the lesion, the great extent of the ulcerous-vegetating process, and the radiological evidences of bone involvement.

The patient should be followed carefully for the development of metastasis. It is true that these patients already suffer, and with some frequency, from several kinds of mutilation and an amputation would increase their limitation to a greater extent. But preservation of life and the possibility of an efficient prosthesis justify such a course of action.

\section{References}

1 Aird I, Johnson HD, Lemox B, Stanfeld AG. Epithelioma cuniculatum. A variety of squamous carcinoma peculiar to the foot. Brit J Surg, 1954; 42: 245.

2 Andersen JG. Malignant degeneration in chronic ulceration of the leg and foot in leprosy patients: two case reports. Lepr Rev, 1982; 53: 265-9.

${ }^{3}$ Becker FT, Walder HJ, Larson DM. Giant condyloma acuminata. Arch Derm, 1969; 100: 184.

${ }^{4}$ Boopalraj JM, Muthusami TC. Squamous cell carcinoma arising from trophic ulcers. Lepr India, 1979; 51: 74-7.

${ }^{5}$ Brownstein $\mathrm{MH}$, Shapiro L. Verrucous carcinoma of skin. Epithelioma cuniculatum plantare. Cancer, 1976; 38: 1710-16.

${ }^{6}$ Dawson DF, Duckworth JK, Bernhardt H, Young JM. Giant condyloma and verrucous carcinoma of genital area. Arch Path, 1965; 79: 225-37.

7 Hayashi Y, Fukuda S. Cancroid from leprotic mal perforans du pied. La Lepro, 1942; 13: 9.

8 Job CK, Riedel RG. Squamous cell carcinoma arising in plantar ulcers in leprosy. Int J Lepr, 1964; 32: 37-44.

9 Judge JR. Giant condyloma acuminatum involving vulva and rectum. Arch Path, 1969; 88: 46-8.

${ }^{10}$ Kraus FT, Perez-Mesa C. Verrucous carcinoma-Clinical and pathological study of 105 cases involving oral cavity, larynx and genitalia. Cancer, 1966; 19: 26-38.

${ }^{11}$ Kulcher GV. Benign and malignant tumors of the foot. JAMA, 1944; 124: 761-6.

12 Leiker DL. Skin carcinoma and leprosy. Trop \& Geographic Med, 1961; 13: 14-19.

13 Martins SRC, Santos HS. Carcinoma espino-celular em úlcera plantar de lepra. Revista Portuguêsa da Doença de Hansen, 1968; 7: 10-3. 


\section{$378 \quad R$ N Fleury \& D V A Opromolla}

${ }^{14}$ Martins de Castro, Martins de Castro Jr. Lepra e tumores malignos: contribuição ao seu estudo anátomo-clínico. Rev Bras Leprol, 1937; 5: 179-222 (especial).

15 Michalany J. Malignant tumors of the skin among leprosy patients. Int J Lepr, 1966; 34: 274-86.

16 Noordeen SK, Srinivasan H. A general study of disability among male leprosy patients above fifteen years age. Int $J$ Lepr, 1966; 34: 159-69.

17 Ochsner PR, Hausman R, Olsthoorn PGM. Epithelioma cuniculatum developing in a neuropathic ulcer of leprous etiology. Arch Orthop Trauma Surg, 1979; 94: 227-31.

18 Periaswamy V, Shastri SV. Carcinoma of trophic ulcer in lepromatous leprosy (letter). Lepr India, 1981; 53: 332.

19 Price EW. Studies on plantar ulcers in leprosy. Lepr Rev, 1959; 30: 98-105.

20 Reingold IM, Smith BR, Graham JH. Epithelioma cuniculatum pedis, a variant of squamous carcinoma. Am J Clin Pathol, 1978; 69: 561-5.

${ }^{21}$ Riedel RG. An additional note on malignancy in plantar ulcers in leprosy. Int J Lepr, 1966; 34: 287-8.

22 Srinivasan H, Desikan KV. Cauliflower growths in neuropathic plantar ulcers in leprosy patients. J Bone Joint Surg, 1971; 53: 123-32.

${ }^{23}$ Troy JL, Grossman ME, Walter RR. Squamous-cell carcinoma arising in a leprous neurotrophic ulcer: report of a case. J Dermatol Surg Oncol, 1980; 6: 659-61. 